\title{
Key Factors of Change Readiness for the Success of Management Innovation in Manufacturing Industry
}

\author{
Seo Shinwon ${ }^{1}$, Park Sunguk ${ }^{1}$, Go Mihyun ${ }^{1}$, Kim Namgyu ${ }^{1}$ and Lim Sunguk ${ }^{2}$ \\ KISTI, 245 Daehak-ro, Yuseong-gu, Daejeon, Korea \\ \{shinwonseo, supark, mihyungo,ssgyu\}@kisti.re.kr \\ ${ }^{2}$ Department of Industrial and Management Enginnering, Deajin University, 1007 \\ Hoguk Road, Pocheon-si, Gyeonggi-do, Korea, sulim@daejin.ac.kr
}

\begin{abstract}
Today, there are many important factors which enterprises should consider to innovate. When there is an organizational change, the employees' understanding of the change and individual readiness that measures the state of readiness are also important factors. Studies have been conducted focusing on the roles of leaders to make a change but for true innovation, all employees should prepare for changes. This study examined 9 domains focusing on the $K$ Company to find out key factors in change readiness. In addition to key factors, this study suggested a plan for employees' effective change management activities by analyzing a perception gap in different positions by factors.
\end{abstract}

Keywords: Change readiness, Innovation, Success factors for projects

\section{Introduction}

Many modern companies have continued to pursue innovation to survive in the changing environment. However, they have difficulties in adapting to changes, and their effort to apply innovation itself in the organization is sometimes resisted (Starbuck \& Hedberg, 1977). Existing studies emphasize organizational learning for a new dimension of organization innovation in this rapidly changing era (Lee Ki-jong \& Lim Young-je, 1996). To enhance capabilities to cope with changes in external environment and competitiveness of an organization, learning is a part of the requirements for employees, but not a whole. This study aims to seek for a change in readiness activity plan suitable for positions by analyzing a perception difference in change readiness factors that employees think of.

This study selected change factors through relevant existing studies and interview with participants in management innovation and consultants who were involved in this field, and to figure out different perceptions in the importance of change factors, it surveyed and analyzed the K Company that is pursuing management innovation.

\section{Theoretical Background}

Studies on corporate management innovation have mainly focused on the presentation of success stories about the introduction and utilization of individual companies' management innovation techniques, and success factors for effective operation methods, or direct impacts on management performance.

To draw reasons for the introduction of successful management innovation, existing studies were reviewed but there were only a few studies on the introduction factors focusing on success factors in management innovation. Therefore, this study carried out a review of literature to find success factors in management innovation and added management innovation readiness factors that are regarded important in the field. 


\subsection{Success Factors in Management Innovation}

Harry explained CEO's leadership, education, innovative organization operation system, assessment, and reward as success factors in management innovation. In a study on success factors focusing on Korean manufacturing industry, Shin Dong-seol (2001) suggested leadership in management, level of innovation activity promoters, and support system. IBM consulting put an emphasis on self-sacrificing leadership, performance measurement methods, reward system, strategy integration, process framework, and proper individual operation. Kim Sang-bu (1999) suggested understanding of management innovation programs, CEO's leadership, data-based management, systematic education and training, and operation system, as success factors. Through a study on success factors focusing on service industry, Kyeong Won Gu (2000) selected leadership, utilization of management innovation methodology (DMAIC), support capabilities of the management, education, and support system, as success factors. Hwang In-cheon (2001) suggested support capabilities of the management, communication, innovative activities, and promoters' capabilities. Kim Hoon-tae (2002) suggested leadership, reward authentication system, promoters' capability and level, education and training, and work standardization, as success factors. Kim Tae-hee and Kim Jong-bin (2202) suggested selection of right projects, use of right tools, formation of right project teams, and establishment of Follow up system. Oh Ji-yeon (2003) suggested initiative leadership, best employees, and establishment of support infrastructures. Yoon Eon-cheol(2003) suggested employees' understanding of innovation programs, validity of measurement methods, operation of exclusive organization, and many experiences of management innovation programs. Park Ju-seok and Kim Dong-su (2004) suggested strong leadership, promoters' level, and support system, selection of right projects, continuous maintenance, and establishment of exclusive organization. Kim Geum-suk and Lee Heug-woo (2005) suggested support infrastructures, propriety of strategies, capabilities of management innovation promoters, and education, as success factors. Ji Jin-ho (2006) suggested preliminary preparation for introduction, leadership of the top management, data-based analysis, education, and support system. Kim Su-yeon and Lee Sang-bok (2006) suggested the support and participation of the top management, innovation activity promoters' capability and level, selection of right projects, continuous education for employees, utilization of proper analysis tools, and consumer oriented management, as success factors.

Considering management innovation promoters and management consultants as well as key factors in the introduction of innovation activities, readiness factors in management innovation are as follows:

Table 1. Key Factors for Change Readiness

\begin{tabular}{|c|c|c|}
\hline Key factors & Definition of key factors & Sub-category \\
\hline \multirow{2}{*}{$\begin{array}{c}\text { Change } \\
\text { understanding }\end{array}$} & $\begin{array}{c}\text { Understanding of project content, target, } \\
\text { goals, and impacts of To-be design on } \\
\text { individuals and an organization }\end{array}$ & 2. Connectivity with vision \\
\cline { 3 - 3 } & $\begin{array}{r}\text { Understanding of the need for changes and } \\
\text { degree of sympathy }\end{array}$ & 3. Need to pursue \\
\cline { 3 - 4 } Appropriateness & 5. Appropriateness \\
\hline $\begin{array}{c}\text { Change } \\
\text { participation }\end{array}$ & Degree of participation in projects & 6. Current participation \\
\hline
\end{tabular}




\begin{tabular}{|c|c|c|}
\hline & & 7. Individual role \\
\hline & & 8. Suggest opinions \\
\hline \multirow{4}{*}{$\begin{array}{l}\text { Change } \\
\text { willingness }\end{array}$} & \multirow{4}{*}{$\begin{array}{l}\text { Willingness to participate in the progress } \\
\text { of projects }\end{array}$} & 9. Attitude towards changes \\
\hline & & $\begin{array}{l}\text { 10. Individual willingness to } \\
\text { participate }\end{array}$ \\
\hline & & $\begin{array}{l}\text { 11. Willingness to receive education } \\
\text { and apply }\end{array}$ \\
\hline & & 12. Willingness to cooperate \\
\hline $\begin{array}{l}\text { Top manager } \\
\text { sponsorship }\end{array}$ & \multirow{2}{*}{$\begin{array}{c}\text { Measure top/middle managers as factors } \\
\text { that help have project direction and } \\
\text { momentum }\end{array}$} & 13. Degree of support \\
\hline $\begin{array}{l}\text { Middle manager } \\
\text { sponsorship }\end{array}$ & & 14. Form sympathy \\
\hline \multirow{2}{*}{$\begin{array}{l}\text { Implementation } \\
\text { management }\end{array}$} & \multirow{2}{*}{$\begin{array}{l}\text { Project implementation/effectiveness of } \\
\text { management methods }\end{array}$} & 15. Authority \& responsibility \\
\hline & & 16. Result management \\
\hline \multirow{2}{*}{ Communication } & \multirow{2}{*}{$\begin{array}{c}\text { Perception of effects of relevant PR, } \\
\text { information delivery, and communication } \\
\text { activities }\end{array}$} & 17. Communication \\
\hline & & 18. Information sharing \\
\hline \multirow{2}{*}{ Culture } & \multirow{2}{*}{$\begin{array}{l}\text { Assessment of the overall atmosphere to } \\
\text { pursue projects }\end{array}$} & 19. Creative atmosphere \\
\hline & & 20. Trust in the progress \\
\hline
\end{tabular}

\section{Empirical Analysis}

This study carries out a survey of the K Company's employees to analyze the importance of management innovation readiness factors by different positions.

\subsection{Analysis Target and Method}

An Off-Line survey was given to 6 offices of the K Company for 10 days from October 20 to 29,2014 . The survey was composed of items such as understanding of an organization, understanding of change readiness capabilities, appropriateness, participation, willingness, manager sponsorship, communication, implementation management, and culture. The survey used a 6-point scale instead of a 5-point scale to prevent central tendency. A total of 265 employees of the K Company were asked to participate in the survey. 253(95\%) employees answered and among them, 2\% were executives, $10 \%$ were team leaders, and $88 \%$ were team members in terms of positions.

\subsection{Analysis Results}

As a result of analysis on the importance of each question, key factors in change readiness were relatively low in individual influence, change, attitude towards changes, and information sharing. 
The important difference by positions showed no differences in attitude towards changes, support, formation of sympathy, and result management among executives, team leaders, and team members. However, other factors showed difference in the importance among them.

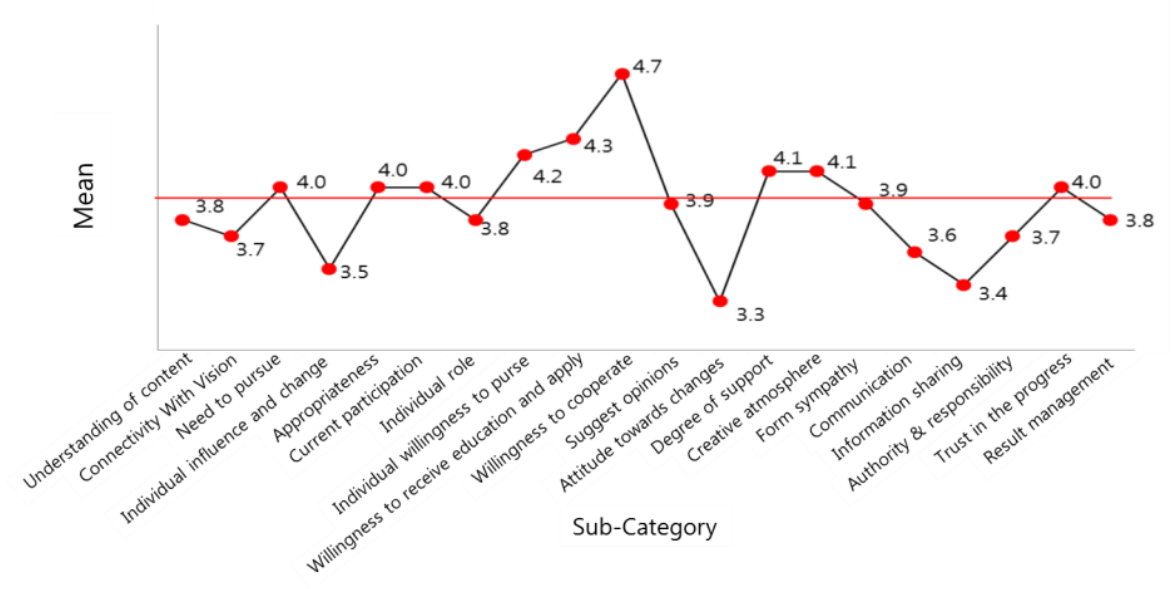

Figure 1. Comprehensive Result by Change Readiness Factors

Table 2. Importance by Positions

\begin{tabular}{|c|c|c|c|c|c|c|c|c|c|c|c|c|c|c|c|c|c|c|c|c|c|}
\hline Category & & $2^{2}$ & 3 & 4 & 5 & 6 & 1 & 8 & 9 & 10 & ${ }_{11}$ & 12 & 13 & 14 & 15 & 16 & 17 & 18 & 19 & & Mea \\
\hline Total & & 4. & 4.0 & 4.5 & 4. & 4 & 4.5 & 4.5 & & 4.7 & 4.6 & 5. & 4.3 & 4. & & 3.7 & 3.9 & & 4.2 & 4.4 & 4.3 \\
\hline Executive & 5. & 5.0 & 4.4 & 5.2 & 5.0 & 4.8 & 5.2 & 5.7 & 2.6 & 5.0 & 4.8 & 5.6 & 4.6 & 4.8 & 4.2 & 4.2 & 4.0 & 4.0 & 4.0 & 4.8 & 4. \\
\hline $\begin{array}{l}\text { Team } \\
\text { leaders }\end{array}$ & & 4.5 & 4.3 & 4.6 & 4.5 & 4.7 & 4.8 & 4.6 & 3.3 & 5.0 & 4.8 & 5.3 & 4.4 & 4.2 & 4.0 & 3.6 & 4.2 & & 4.6 & 4.6 & \\
\hline $\begin{array}{l}\text { Team } \\
\text { members }\end{array}$ & & 3.6 & 3.4 & 3.8 & 3.9 & 3.9 & 3.6 & 3.8 & 3.3 & 4.1 & 4.2 & 4.6 & 4.0 & 3.8 & 3.6 & 3.3 & 3.6 & 3.7 & 4.0 & 3.9 & \\
\hline -value & 0.0 & 0.00 & 0.00 & 0.00 & 0.00 & 0.00 & 0.00 & 0.00 & 0.88 & 0.00 & 0.00 & 0.00 & 0.14 & 0.06 & 0.01 & 0.03 & 0.00 & 0.00 & 0.00 & 0.00 & \\
\hline
\end{tabular}

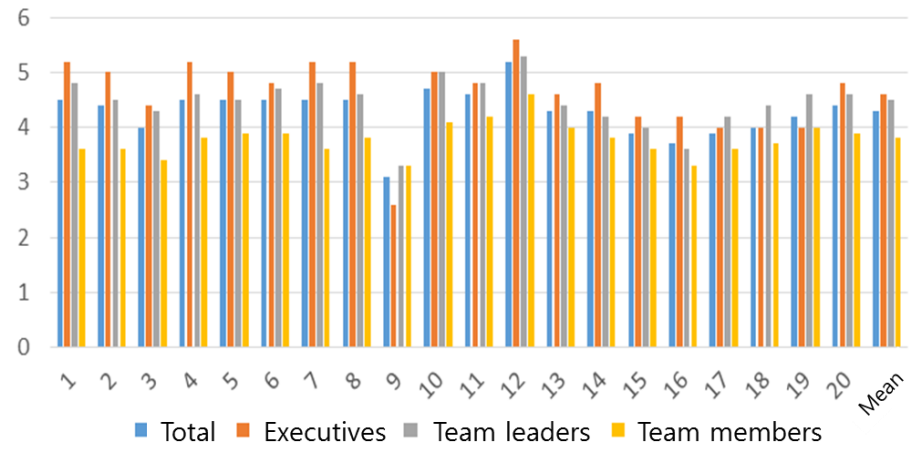

Figure 2. Change Readiness Factors \& Result by Positions

Q1> for innovation projects, concepts, scope to pursue, and goals of the projects are important.

The above item is found to be statistically significant in position as P-value is 0.000 . Team members show differences between team leaders and executives in terms of concept of innovation projects, scope to pursue, and goals, and this means it needs to clarify the scope and goals to pursue innovation projects. 


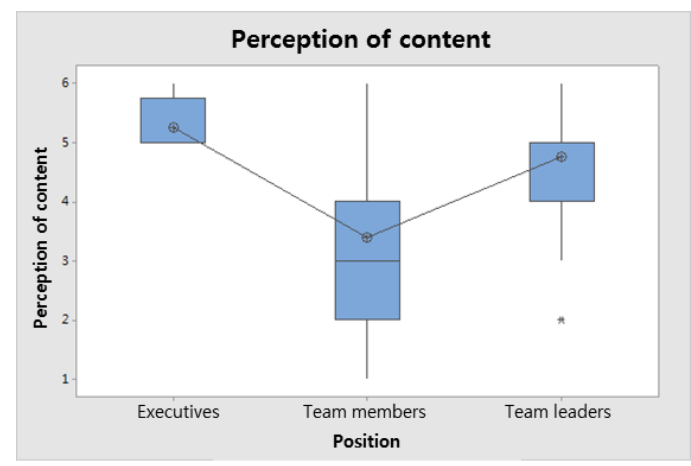

Figure 3. Perception of Content

Q2> Relationship between innovation project and the company' s achievement of vision is important.

The above item is statistically significant in position as P-value is 0.000 . This shows how changes caused by GDI activities are related to the company' s vision achievement, which means it needs to enhance communication to form relevant sympathy.

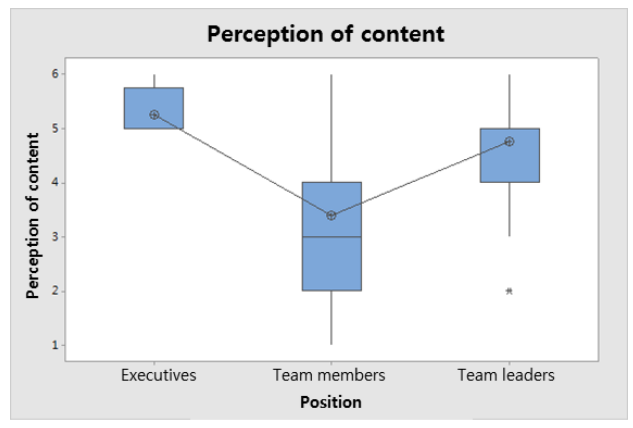

Figure 4. Connectivity with Vision

Q3> Relationship between innovation projects and work is important.

The above item is statistically significant in position as P-value is 0.000 . This means that it needs to actively promote the utilization scope of GDI and success stories to team members.

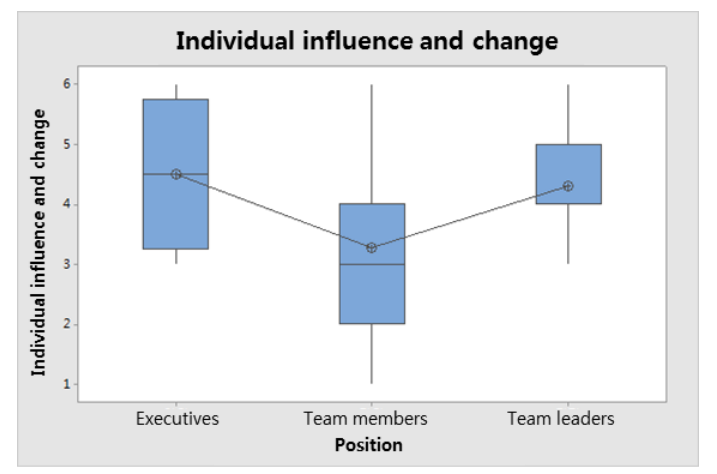

Figure 5. Individual Influence and Change

Q4> It is critical to share clear reasons and need to pursue innovation projects.

The above item is statistically significant in position as P-value is 0.000. Especially, this means that team leaders need to understand the reason for GDI projects and appropriateness. Thus, in terms of change management, organization members need to be 
aware of the importance of corporate changes and innovation prior to corporate changes and efforts for innovation.

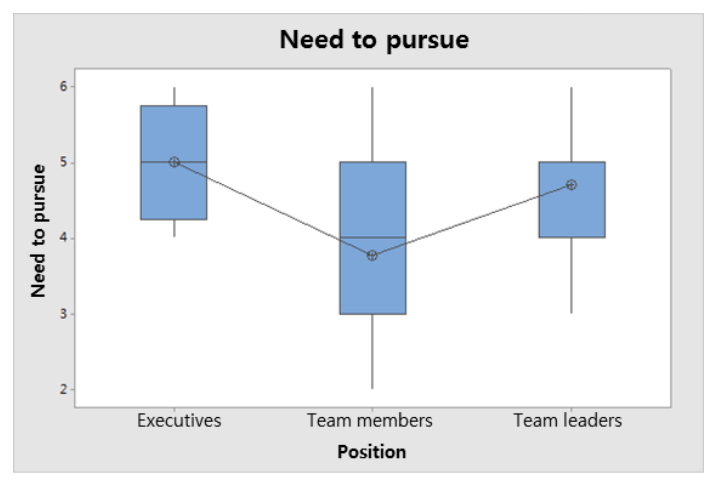

Figure 6. Need to Pursue

Q5> Innovation projects are essential to raise competitiveness of the company.

The above item is statistically significant in position as P-value is 0.002 . Top leaders or higher superiors need to make much effort to help team leaders understand the importance of GDI projects. To this end, leaders' initiative and innovative leadership are more important than ever before.

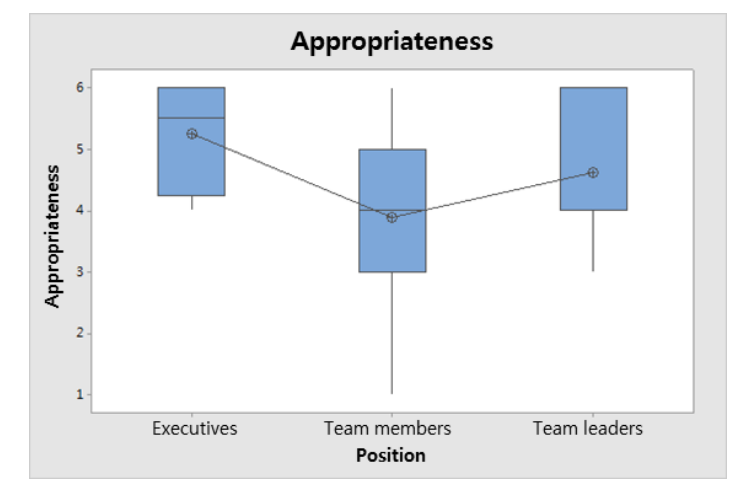

Figure 7. Appropriateness

Q6> to pursue innovation projects, strong team (organization) connectivity is important.

The above item is statistically significant in position as P-value is 0.0003 . It indicates that team members of different positions have relatively negative view about team participation, so prior education is required.

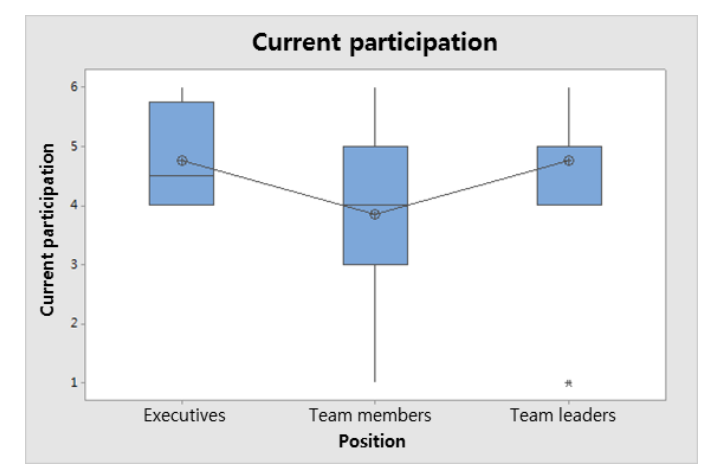

Figure 8. Current Participation 
Q7> The roles to pursue successful innovation projects should be well informed.

The above item is statistically significant in position as P-value is 0.000 . Team members lack in understanding the roles to lead successful GDI activities. To solve this problem, team leader level, the pillar of corporate innovative activities should play a role in reminding team members of the roles.

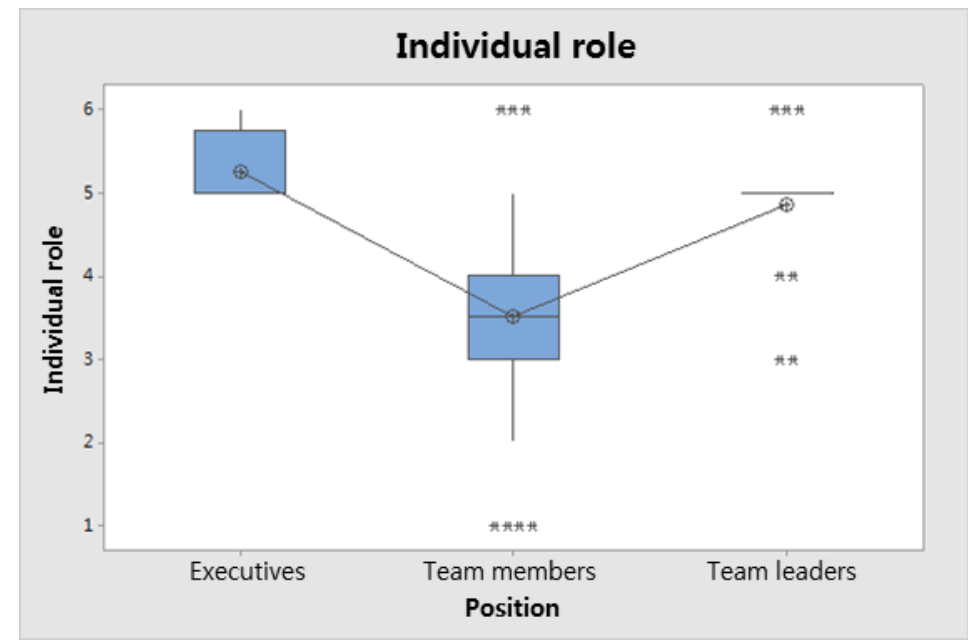

Figure 9. Individual Role

Q8> It is important that organization members are encouraged to raise their sound opinion about innovation project changes.

The above item is statistically significant in position as P-value is 0.000 . It seems that the culture of the target company has a problem in actively suggesting an opinion regarding change and innovation. Companies with such culture require team leader levels to find out the problem and solve them, in terms of the establishment of corporate culture for creative change and innovation.

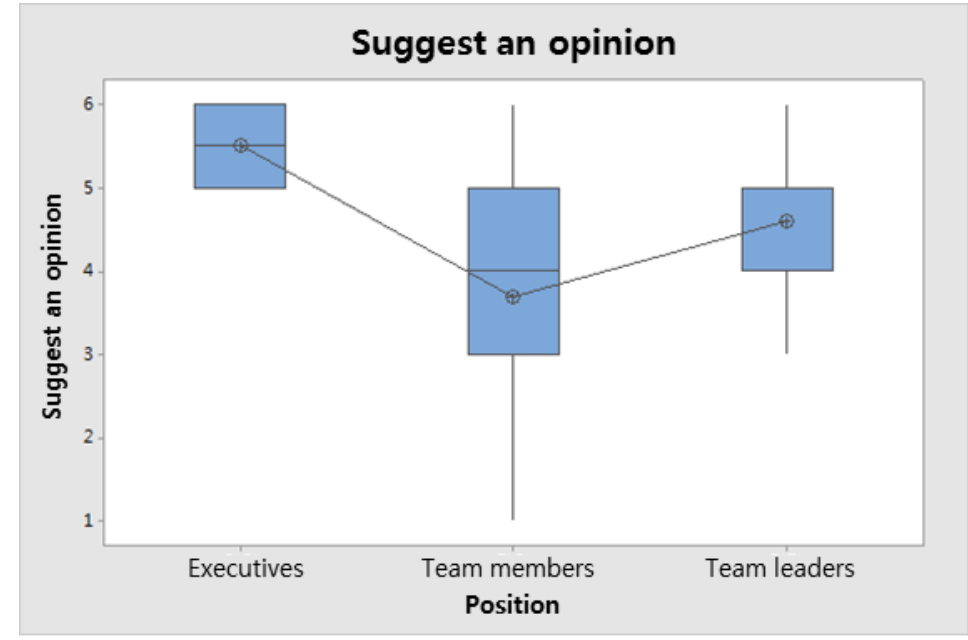

Figure 10. Suggest an Opinion

Q9> Changes caused by innovation projects are largely related to individual attitudes and behaviors.

The above item indicates that there is no statistical significance in position as P-value is 0.888 . It doesn' t show statistical difference, but the assessment result seems relatively low compared to previous facts. This is counterevidence where organization members are 
still unsure about corporate change and effort for innovation, so change management is required.

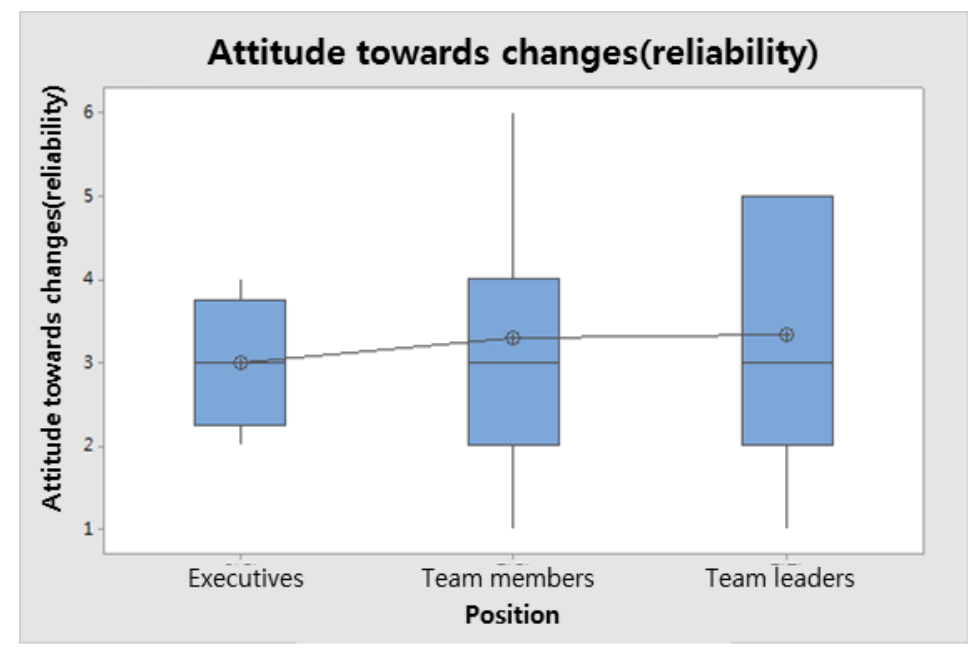

Figure 11. Attitude towards Changes

Q10> It is important to actively participate in innovation projects.

The above item is statistically significant in position as P-value is 0.003 . It seems that team members still lack in efforts to actively cope with changes compared to immediate superiors. Therefore, team leader level needs to take initiative and possess leadership for innovation.

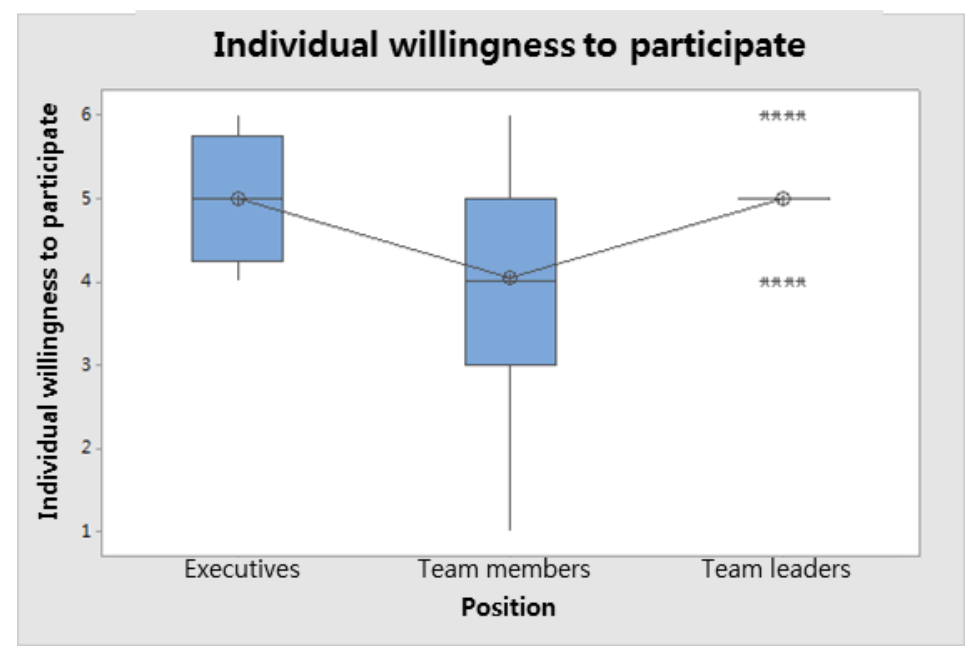

Figure 12. Individual Willingness to Participate

Q11> It is important to learn about the skills and behaviors necessary for changes from innovation projects and voluntarily put them into action at work.

The above item is statistically significant in position as P-value is 0.007 . This directly indicates that it can be difficult to learn and acquire new things. 


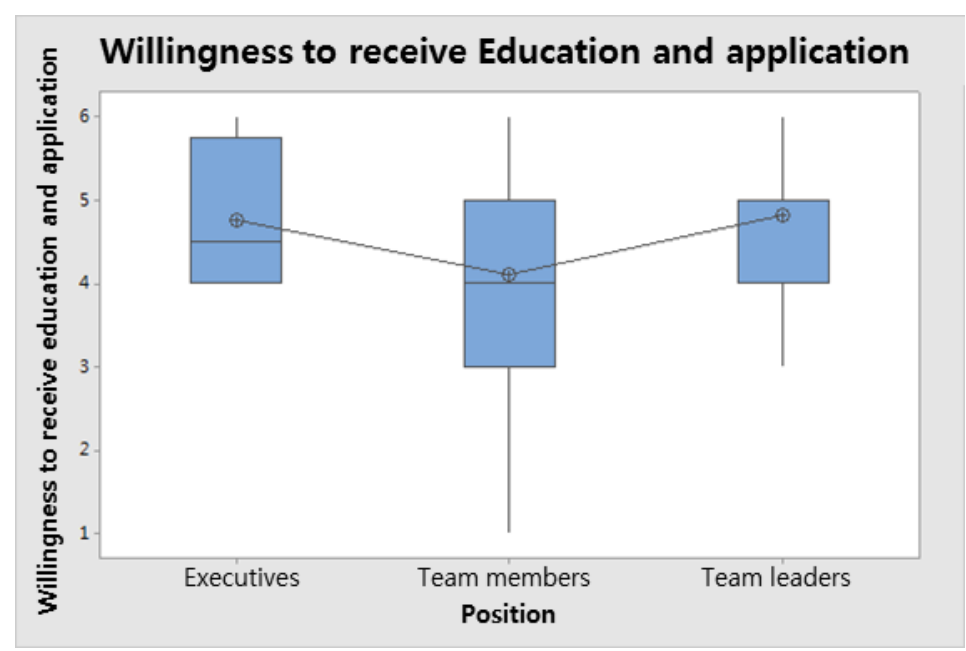

Figure 13. Willingness to Receive Education and Apply

Q12> Active cooperation is necessary for projects to be successful.

The above item is statistically significant in position as P-value is 0.000 . It seems that team members' willingness to cooperate is lower than previous facts. If it is one of the characteristics of the company, the reason must be analyzed.

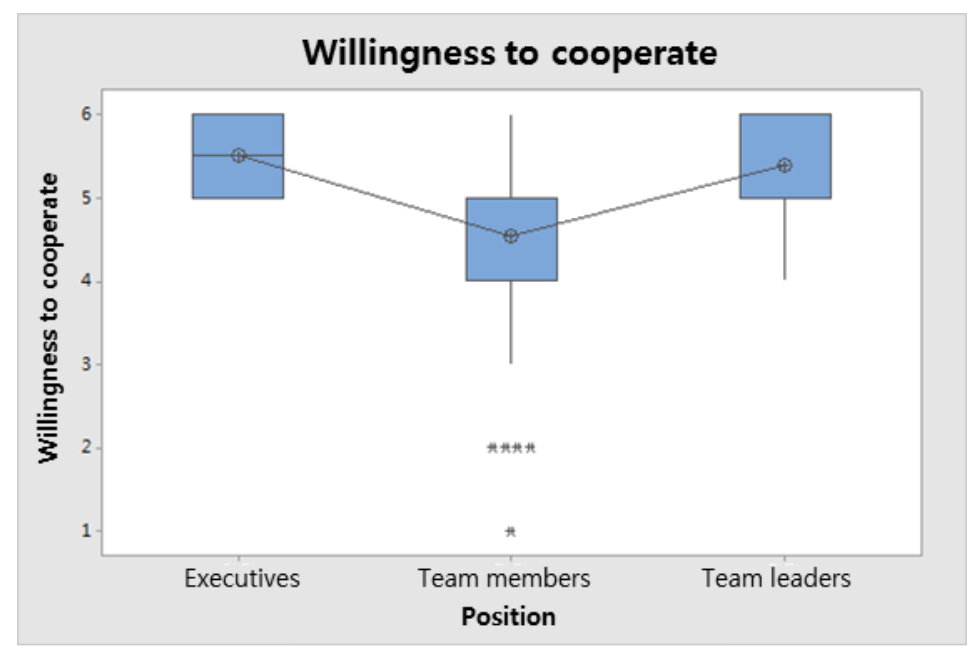

Figure 14. Willingness to Cooperate

Q13> The management and executives of the company need to have sincere interest in pursuing successful innovation projects and provide much assistance.

The above item doesn' t show statistical significance in position as P-value is 0.142. Although this doesn' t show a statistical difference, the assessment result for team members is relatively lower. This may be resulted from difficulty in suggesting an opinion due to organizational hierarchy, and at the very worst, from indifference. 


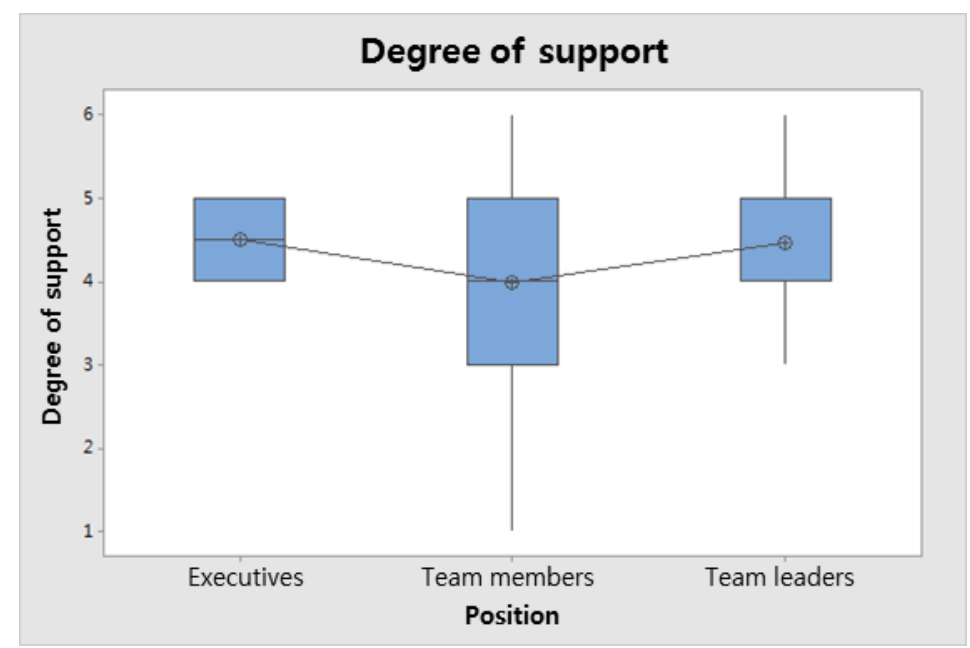

Figure 15. Support

Q14> Superiors should be able to fully understand and explain the reason for pursuing innovation projects and future goals.

The above item doesn't show statistical significance in position as P-value is 0.065 . The assessment for team members has relatively larger dispersion than team leader level. Therefore, future verification for this item is necessary.

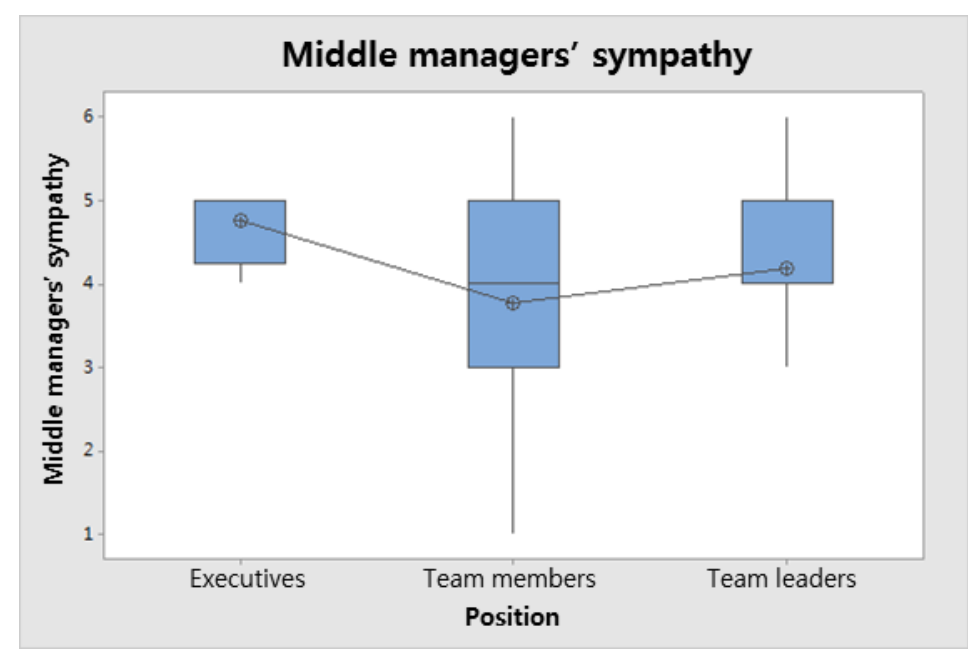

Figure 16. Formation of Sympathy

Q15> Everyone involved in project changes should fully understand the innovation project and be aware of the progress well.

The above item is statistically significant in position as $\mathrm{P}$-value is 0.014 . This shows a different result from Q14. In particular, team members express relatively negative opinions about questionnaires, so there is a need for taking interest and care for team members. 


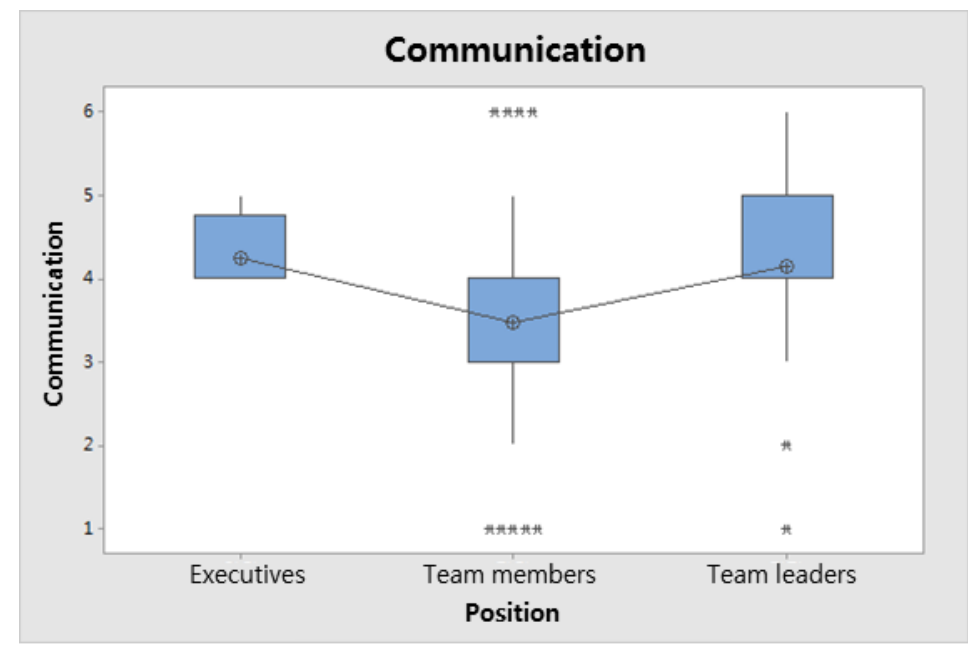

Figure 17. Communication

Q16> Everyone involved in innovation project should know where they can find information about projects.

The above item is statistically significant in position as $\mathrm{P}$-value is 0.039 . This means that team members relatively express difficulties in obtaining relevant information, so it needs to establish total infrastructures for sharing GDI related information.

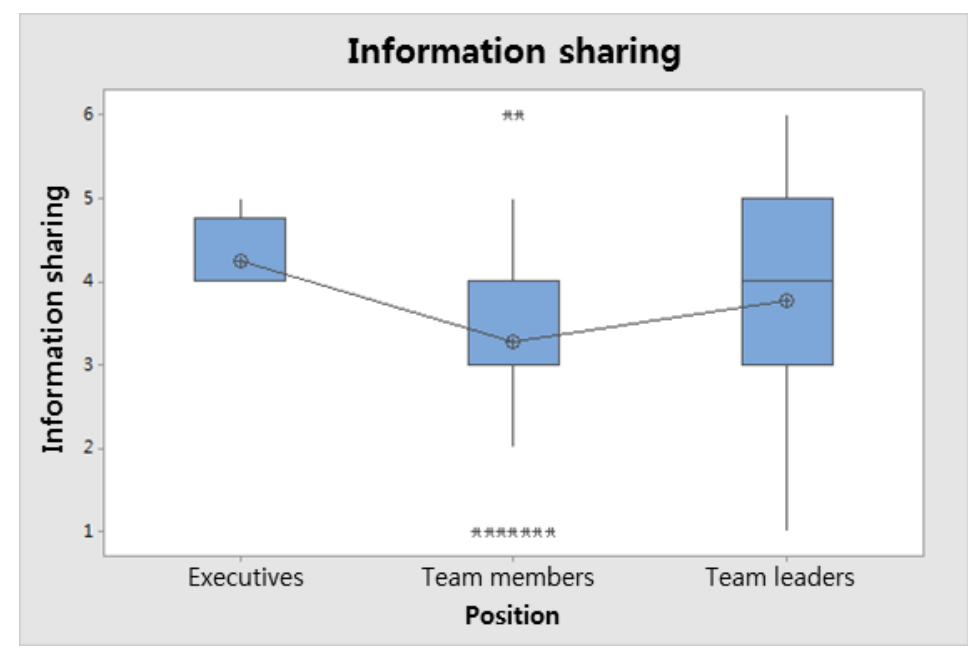

Figure 18. Information Sharing

Q17> Authority and roles to achieve changes from innovation project should be clarified.

The above item is statistically significant in position as P-value is 0.004 . Team members think that authority and roles are not relatively clear, and therefore the relevant delegation of authority must be reviewed. 


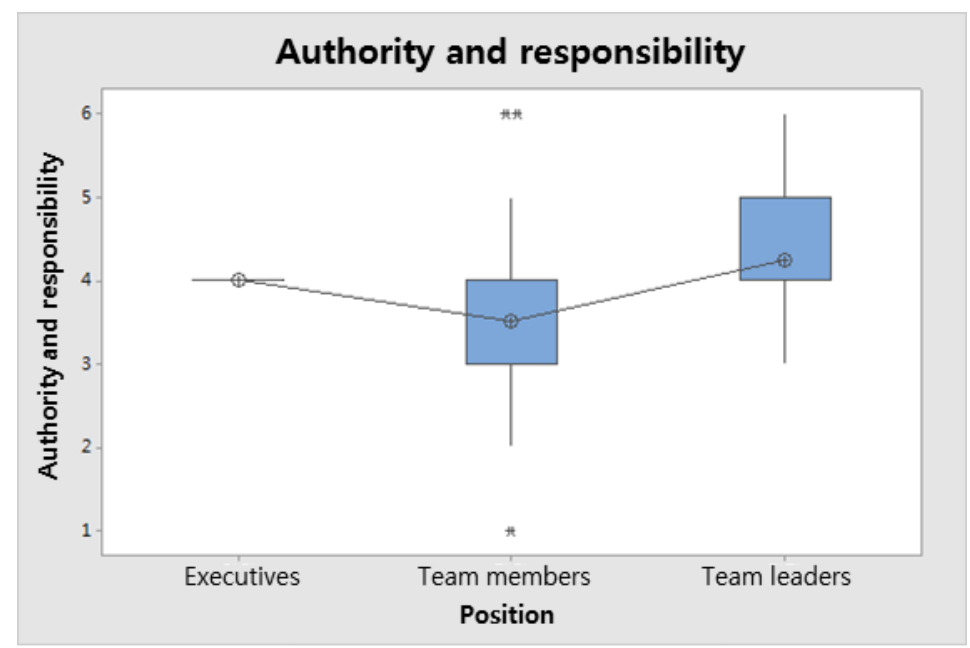

Figure 19. Authority and Responsibility

Q18> Team members who are active in changes from innovation project must be rewarded, and punished if they don't adapt to it well.

The above item is statistically significant in position as P-value is 0.001 . In particular, team members show an objection to the above question. Therefore, it needs to clarify the outcome, standard, and procedures for GDI activities.

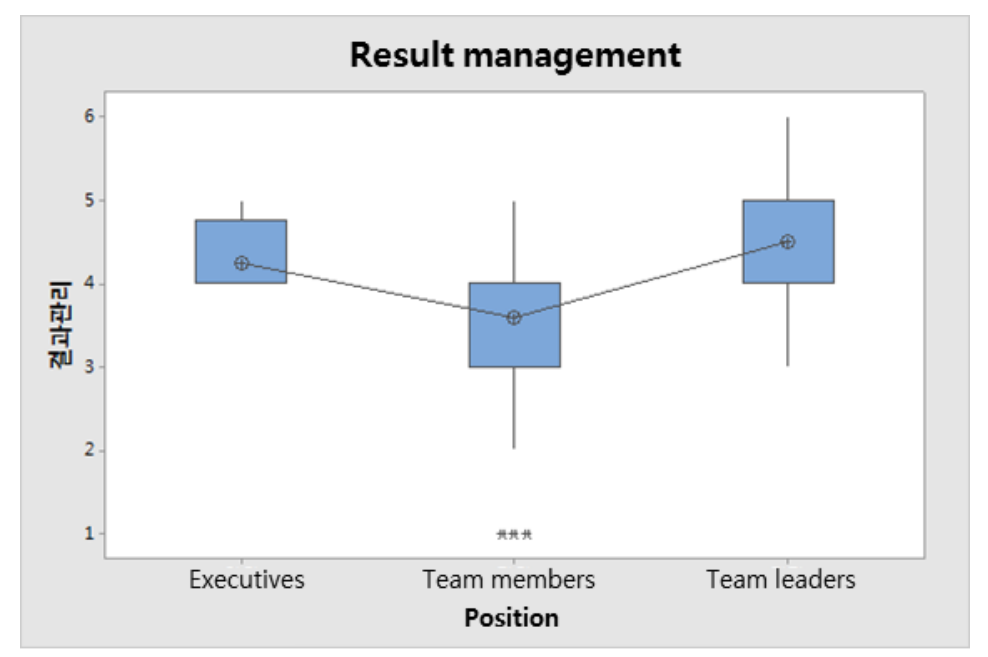

Figure 20. Result Management

Q19> The management and executives of the company should promote new ideas and ways to accomplish the given task.

The above item is statistically significant in position as P-value is 0.009. Team members answer negatively to the above question. Therefore, the management and leaders should put much effort for building creative organizational culture. 


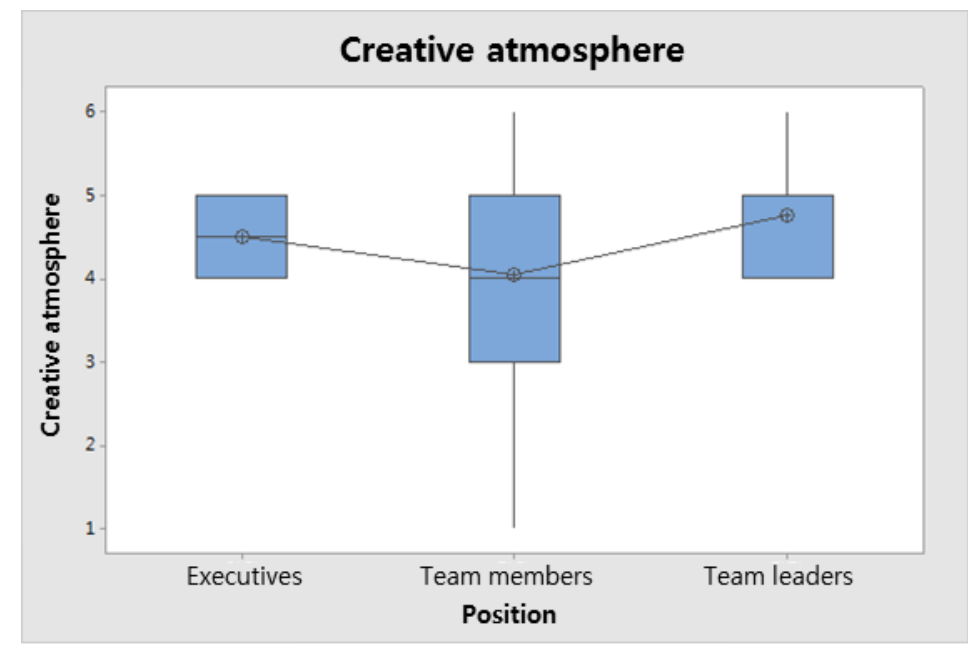

Figure 21. Creative Atmosphere

Q20> The progress of innovation projects should be trustworthy.

The above item is statistically significant in position as P-value is 0.002 . Team members have relatively negative attitude in the progress. Therefore, team leaders or higher level should be responsible for finding ways to improve sharing the progress and double trust.

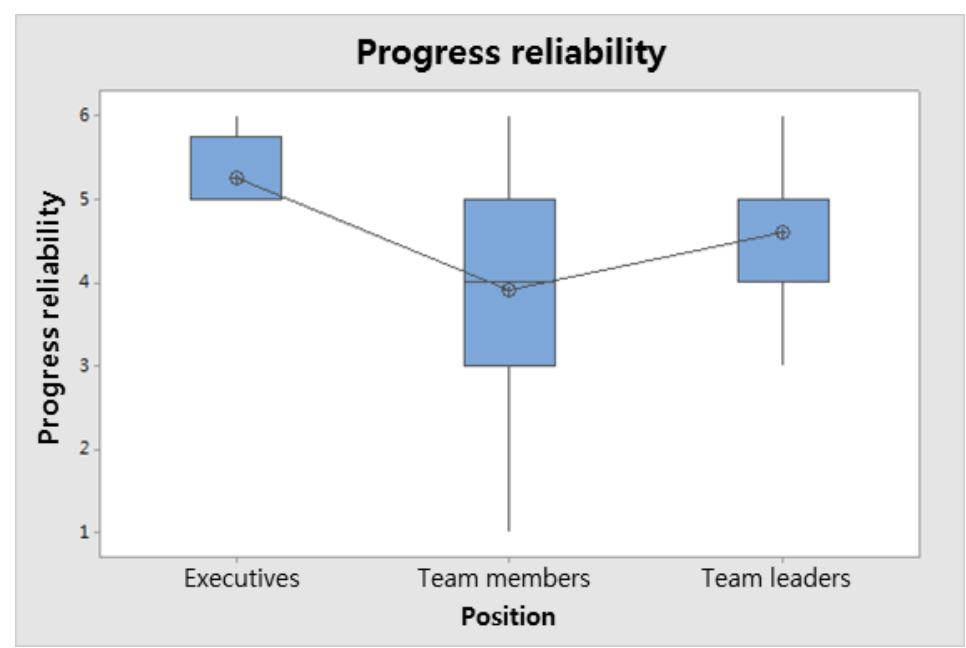

Figure 22. Reliability of Progress

\section{Conclusion and Limit}

This study draw key factors in preparation for the introduction of new management innovation techniques, and as the result of analysis of importance by positions, the following conclusions were drawn. First, communication activities to enhance understanding of projects should be strengthened. Second, it needs to continuously inform employees of the changes resulting from management innovation activities and collect their opinion. Third, a channel to share progress and result (performance) is required. Fourth, strong leadership of the management is required.

Lastly, the factors of difference in importance among executives, team leaders, and team members may have the effect on right education only when education tailored to each position is given. This study conducted a survey in only one company, so it has a limit to have an impact of internal propensity of the company. Therefore, further study 
needs to carry out additional survey analysis of various companies and types of businesses.

\section{References}

[1] S. Young-Ju, "A Study on the Selection of Six - Sigma Project by TP Method", Graduate School of Ajou University, (2000).

[2] A. Gyeong-Seop and Y. Mi-Jeon, "The Relationship between Direction of Innovative Activities in Public Institutions and Organizational Performance”, Korean Association for Policy Sciences, vol. 13, no. 1, (2009), pp. 51-74.

[3] O. Eul-Im, K. Gu and B. Yong-Tae, "The Effects of Organizational Learning on Organizational Change and Performance in Local Public Agency”, Korean Society \& Study on Administration, vol. 13, no. 3, (2002), pp. 207-237.4.

[4] J. A. Blakeslee, et al., "Implementing the Six Sigma Solution", Quality Progress, vol. 34, no. 3, (1999), pp. 66-72.

[5] R. H. Draman and S. S. Chakravorty, "An Assessment of Quality Improvement Project Selection Alternatives", Quality Management Journal, vol. 7, no. 1, (1999), pp. 58-73.

[6] M. J. Harry, "Six Sigma: A Breakthrough Strategy for Profitability", Quality Progress, vol. 33, no. 5, (1998), pp. 60-64.

[7] M. J. Harry, “The Quality Twilight Zone”, Quality Progress, (2000) February, pp. 68-71.

[8] Z. Steve, "Six Sigma BB Training", SBTI, (2000).

[9] S. Shinwon, P. Sunguk, G. Mihyun, K. Namgyu and L. Sunguk, "Key Factors of Change Readiness for the Success of Management Innovation: Focusing on the K Company", Advanced Science and Technology Letters, vol. 102, (2015), pp. 59-63.

[10] C. Perng, S.-L. Wang and W.-C. Chiou, "A Conceptual Framework of Library Reader Service from Customer Relationship Management Perspective", IJAST, vol. 2, (2009) January.

[11] Q. Y. Dai, R. Y. Zhong, M. L.Wang, X. D. Liu and Q. Liu, "RFID-enable Real-time Multi-experiment Training Center Management System”, IJAST, vol. 7, (2009) June.

[12] F. Y. Sattarova, S. Y. Shavkat and T. A. Furkhat and T.-H. Kim, "Model of Business Service Management with Security Approach", IJAST, vol. 9, (2009) August. 